\title{
Recrystallized microstructures and mechanical properties of a C-containing CoCrFeNiMn-type high-entropy alloy
}

\author{
M.V. Klimova ${ }^{a}$,*, D.G. Shaysultanov ${ }^{a}$, R.S. Chernichenko ${ }^{a}$, V.N. Sanin ${ }^{b}$, N.D. Stepanov ${ }^{a}$, \\ S.V. Zherebtsov", A.N. Belyakov ${ }^{\mathrm{a}}$ \\ ${ }^{a}$ Belgorod State University, Pobeda 85, Belgorod 308015, Russia \\ ${ }^{\mathrm{b}}$ Merzhanov Institute of Structural Macrokinetics and Materials Science, Russian Academy of Sciences, Chernogolovka, Moscow 142432 Russia
}

\section{A R T I C L E I N F O}

\section{Keywords:}

High-entropy alloys

Phase transformation

Grains and interfaces

Electron microscopy

Stress/strain measurements

\begin{abstract}
A B S T R A C T
The effect of cold rolling to $80 \%$ thickness reduction and annealing at $973-1373 \mathrm{~K}$ for $1 \mathrm{~h}$ on the microstructure and mechanical properties of a C-containing CoCrFeNiMn high-entropy alloy was studied. Cold rolling significantly strengthened the alloy to the yield strength of $1310 \mathrm{MPa}$. Annealing at $973 \mathrm{~K}$ or $1073 \mathrm{~K}$ resulted in incomplete recrystallization of an fcc matrix and $\mathrm{M}_{23} \mathrm{C}_{6}$-type carbide precipitations aligned with highly elongated grains/subgrains. Complete recrystallization occurred during annealing at $1173-1373 \mathrm{~K}$. The ordered arrangement of the carbides was not observed after annealing at $1273 \mathrm{~K}$ or $1373 \mathrm{~K}$. The volume fraction of carbides decreased with increasing the annealing temperature that can be reasonably described by a ThermoCalc prediction. The coarsening behavior of the microstructure constituents was studied during isothermal annealing at $1173 \mathrm{~K}$ for $1-50 \mathrm{~h}$. It was found that the grain growth and the particle coarsening can be expressed by power law functions of annealing time with grain/particle size exponents of about 2 and 3, respectively. An increase in the annealing temperature from $973 \mathrm{~K}$ to $1373 \mathrm{~K}$ led to a gradual softening of the alloy; the yield strength decreased from $870 \mathrm{MPa}$ to $320 \mathrm{MPa}$, whereas total elongation increased from $24 \%$ to $47 \%$, respectively. Contributions of various strengthening mechanisms into the overall strength of the alloy were discussed.
\end{abstract}

\section{Introduction}

High-entropy alloys (HEAs), which are considered as a subclass of so-called complex, concentrated alloys (CCAs), have recently attracted a great deal of attention from the materials scientists worldwide [1-3]. The main idea behind HEAs/CCAs is the development of alloys with a complex chemical composition, containing multiple (generally 5 and more) principal elements, in contrast to conventional alloys, which are mostly based on a single principal element. It is believed that HEAs can possess unique structures and properties that cannot be obtained in conventional materials [3-5]. The available results confirm ample opportunities for the development of HEAs/CCAs with attractive properties, such as high specific strength at elevated temperatures, a combination of high strength and ductility at room temperature, and recordbreaking toughness at low temperatures [5-14].

The most studied class of HEAs is late $3 \mathrm{~d}$ transition element alloys [3]. One of typical examples is the equiatomic CoCrFeNiMn alloy, also known as the Cantor alloy $[15,16]$. This alloy has a single face centered cubic (fcc) structure stable at $\mathrm{T} \geq 900{ }^{\circ} \mathrm{C}$ [17-20], and possess promising mechanical properties, namely high ductility and toughness at room temperature, which increases even further at cryogenic temperatures $[12,21,22]$. The attractive properties of the alloy at cryogenic temperatures were ascribed to a synergy of different deformation mechanisms, including nanotwinning $[12,13,22]$. Meanwhile the contribution of nanotwinning to plastic deformation of the alloy at room temperature remains debatable [22-25].

However, the yield strength of the CoCrFeNiMn alloy at room temperature is rather low $[21,22]$. This problem is typical of single fcc phase HEAs based on 3d transition metals [3,26]. A proper tailoring of the chemical composition along with microstructure modification using thermal/thermomechanical treatment resulted in alloys, which showed a significant increment in strength without sacrifice in ductility due to the formation of fine fcc grains and/or nanoscale precipitates of second phase(s) [10,14,27-34]. The most significant strengthening was found to be induced by nanoscale precipitates (e.g. Al, Ni-rich $\mathrm{L}_{2} / \mathrm{B} 2$ type phases) [10,14,27-30].

Meanwhile, interstitial alloying with elements like carbon can efficiently increase the strength of 3d transition metal fcc HEAs without considerable loss in ductility; mostly due to a strong solid-solution strengthening effect $[9,35-45]$. In addition, carbon can change the

\footnotetext{
* Corresponding author.

E-mail address: klimova_mv@bsu.edu.ru (M.V. Klimova).
} 
contributions of operating deformation mechanisms due to stackingfault energy (SFE) changing. It should be noted, however, that different sources claim both increase [44-46] and decrease [9,38,39] of the twinning intensity with the change of SFE. Much smaller attention has been paid so far to precipitation hardening of HEAs by fine carbide particles. For example, Cr-rich $\mathrm{M}_{23} \mathrm{C}_{6} / \mathrm{M}_{7} \mathrm{C}_{3}$ carbides can be found in Co-Cr-Fe-Ni-Mn system HEAs in as-cast, heat treated, and thermo-mechanically processed conditions [9,35,42]; yet in most cases the reported carbide particles were coarse and did not result in noticeable strengthening $[36,42,46]$.

Therefore, in the present work we have studied the evolution of microstructure and mechanical properties during annealing of a CoCrFeNiMn-type HEA containing interstitial carbon. The program alloy was produced by the self-propagating high-temperature synthesis method (SHS) $[14,32,47]$. Annealing of the cold-rolled alloy was carried in a temperature range of $973-1373 \mathrm{~K}$, which, according to previous results $[20,22,35,36,38,42,48]$, could lead to recrystallization of the fcc matrix and/or precipitation of carbide particles. Detailed microstructural investigations and tensile testing of the annealed alloy were performed, and links between the microstructure parameters and mechanical properties of the alloy were established.

\section{Materials and methods}

The program material, i.e., a C-containing CoCrFeNiMn-type highentropy alloy, was produced by self-propagating high-temperature synthesis (SHS). Powders including oxides of the target elements of $\mathrm{NiO}, \mathrm{Cr}_{2} \mathrm{O}_{3}, \mathrm{Co}_{3} \mathrm{O}_{4}, \mathrm{Fe}_{2} \mathrm{O}_{3}, \mathrm{MnO}_{2}$ and pure $\mathrm{C}$, and $\mathrm{Al}$ with a total weight of $1200 \mathrm{~g}$ were mixed and combusted in a graphite mould of $80 \mathrm{~mm}$ in diameter. A centrifugal SHS setup was used since previous studies have demonstrated that the SHS process carried out under high gravity conditions allows the best separation of the target product (ingot) from the slag $\left(\mathrm{Al}_{2} \mathrm{O}_{3}\right)$ and convective mixing of all alloy components; the latter is particularly important in CCAs with an increased number of components [47]. The SHS-produced alloy was re-melted using induction furnace and cast into an ingot measuring $40 \mathrm{~mm}$ diameter and $80 \mathrm{~mm}$ length. The measured chemical composition of the resulting ingot is shown in Table 1.

Slabs with a thickness of $5 \mathrm{~mm}$ were cut from the ingot by an electric discharge machine and then rolled in few passes at room temperature with a total rolling reduction of $80 \%$. The reductions per pass were $5-10 \%$. After rolling to the final thickness, the samples were annealed in a muffle furnace in air atmosphere at temperatures of $973 \mathrm{~K}$, $1073 \mathrm{~K}, 1273 \mathrm{~K}$ or $1373 \mathrm{~K}$ for $1 \mathrm{~h}$ and at $1173 \mathrm{~K}$ for $1-50 \mathrm{~h}$ followed by air cooling.

Microstructure was studied using X-ray diffraction (XRD) analysis, transmission (TEM) and scanning (SEM) electron microscopy. XRD analysis was performed using a RIGAKU diffractometer with $\mathrm{Cu}$ K- $\alpha$ irradiation. Microstructural investigations were carried out on sample sections perpendicular to the transverse direction. Samples for SEM observations were mechanically polished in water with different SiC papers and a colloidal silica suspension; the final size of the $\mathrm{Al}_{2} \mathrm{O}_{3}$ abrasive was $0.04 \mu \mathrm{m}$. SEM back-scattered electron (BSE) images were obtained using a FEI Quanta 200 3D microscope. TEM investigations were carried out using a JEOL JEM-2100 microscope with an accelerating voltage of $200 \mathrm{kV}$. Samples for TEM analysis were prepared by conventional twin-jet electro-polishing in a mixture of $90 \% \mathrm{CH}_{3} \mathrm{COOH}$

Table 1

Experimentally measured chemical composition of the C-containing CoCrFeNiMn-type alloy.

\begin{tabular}{llllllll}
\hline Element & Co & Cr & Fe & Ni & Mn & Al & C \\
\hline at $\%$ & 22.35 & 19.67 & 22.85 & 22.44 & 8.62 & 3.37 & 0.69 \\
wt $\%$ & 23.92 & 18.57 & 23.17 & 23.92 & 8.64 & 1.65 & 0.15 \\
\hline
\end{tabular}

and $10 \% \mathrm{HClO}_{4}$ at room temperature.

Tensile tests were carried out at room temperature using dog-boneshaped flat specimens with gauge dimensions of $6 \mathrm{~mm}$ length $\times 3 \mathrm{~mm}$ width $\times 1 \mathrm{~mm}$ thickness. The specimens were tensioned at an initial strain rate of $10^{-3} \mathrm{~s}^{-1}$ using an Instron 5882 test machine. At least two specimens were tested for each condition. The elongation to fracture was determined by measuring spacing between marks designating the gauge length before and after the test. The structural changes during the tensile test of the alloy after annealing at $1173 \mathrm{~K}$ for $1 \mathrm{~h}$ were studied by TEM using the specimens, which were tensioned to $5 \%$ or $22 \%$ elongation. The microhardness of the specimens was examined using Vickers microhardness testing with a load of $0.3 \mathrm{~kg}$. The hardness values were averaged over at least 20 individual measurements per each data point.

Equilibrium phase diagram was constructed using a Thermo-Calc (version 2017a) software employing a TCHEA2 (high-entropy alloys) database.

\section{Results}

\subsection{Cold rolled microstructures}

Deformation microstructure of the carbon-containing CoCrFeNiMntype high-entropy alloy obtained by cold rolling ( $80 \%$ reduction) is shown in Fig. 1. The large strain cold rolling resulted in the development of a lamellar-type microstructure consisting highly flattened grains/subgrains with the transverse size of about $250 \mathrm{~nm}$. High dislocation density and closely spaced grain/subgrain boundaries in the cold rolled microstructure resulted in significant strengthening of the alloy; the hardness was found to be $3850 \mathrm{MPa}$. It is worth noting that the microstructure after cold rolling looks like a single-phase fcc-solid solution without the presence of any second phase(s) particles.

\subsection{Annealed microstructures}

\subsubsection{Isochronal annealing}

The effect of annealing temperature on the hardness of cold rolled samples is shown in Fig. 2. Annealing at $973 \mathrm{~K}$ for $1 \mathrm{~h}$ did not soften the alloy considerably; the hardness decreased from $3850 \mathrm{MPa}$ to $3470 \mathrm{MPa}$. However, further increase in the annealing temperature to $1073 \mathrm{~K}$ resulted in a remarkable decrease in the hardness to $2590 \mathrm{MPa}$. Then, the hardness almost linearly decreased with an increase in the temperature, approaching $1910 \mathrm{MPa}$ after annealing at $1373 \mathrm{~K}$. The drastic softening at $973-1073 \mathrm{~K}$ was most likely associated with primary static recrystallization, which could readily develop in the cold rolled samples.

Typical microstructures, which formed in the cold rolled alloy

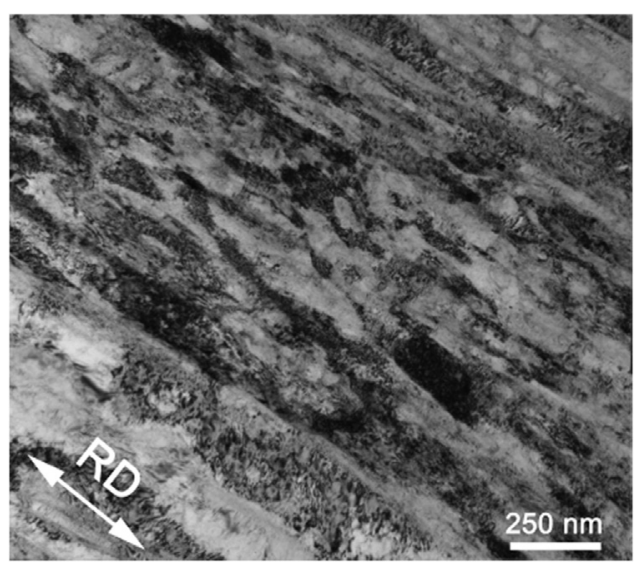

Fig. 1. Microstructure of the C-containing CoCrFeNiMn-type alloy after $80 \%$ cold rolling. 


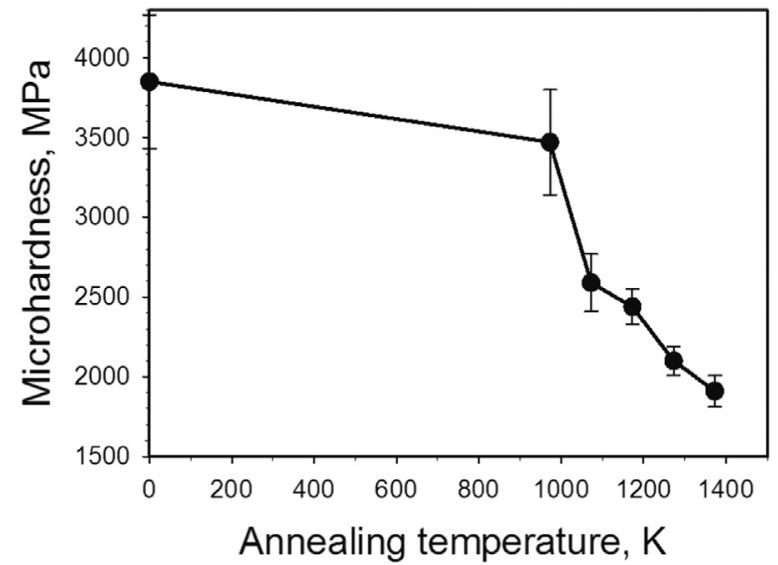

Fig. 2. Effect of annealing temperature on the microhardness of the C-containing CoCrFeNiMn-type alloy.

during annealing for an hour at temperatures of 973-1373 K, are shown in Fig. 3. As it was suggested above, annealing at $973-1073 \mathrm{~K}$ induced the onset of recrystallization, which was found to be incomplete at these temperatures, however. The corresponding microstructures consisted of deformed areas and equiaxed recrystallized grains containing a high density of annealing twins (Fig. 3a and b). An increase in the annealing temperature to $1173-1373 \mathrm{~K}$ gave rise to complete recrystallization (Fig. $3 \mathrm{c}$ to e). The average grain size in the recrystallized microstructures increased with an increase in the annealing temperature.

Temperature dependencies of the recrystallized fraction and recrystallized grain size are shown in Fig. 4. The recrystallized fraction increased from 0.6 to 1.0 with an increase in the annealing temperature from $973 \mathrm{~K}$ to $1173 \mathrm{~K}$. The size of recrystallized grains was $2.8 \mu \mathrm{m}$ after

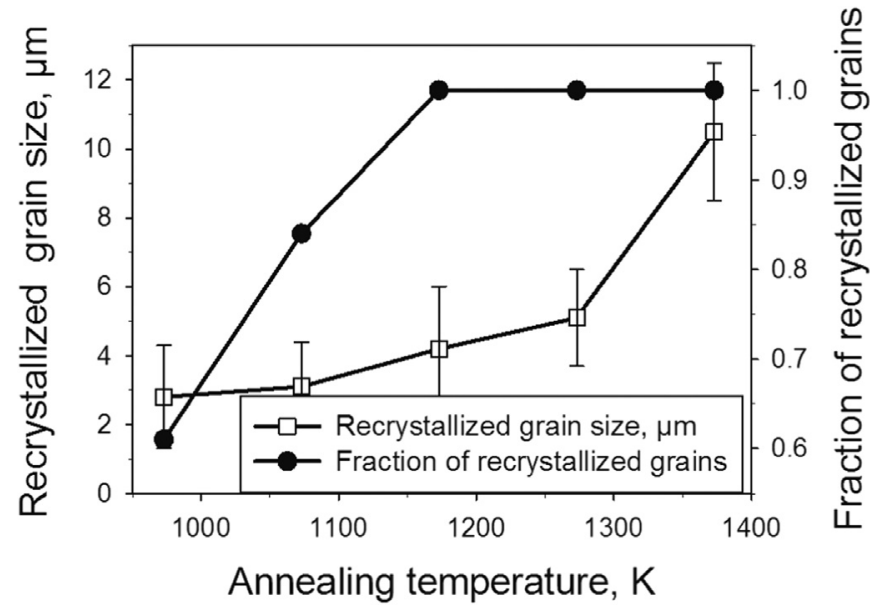

Fig. 4. Dependence of the recrystallized volume fraction and recrystallized grain size of the C-containing CoCrFeNiMn-type alloy on annealing temperature.

annealing at $973 \mathrm{~K}$. An increase in the annealing temperature to $1273 \mathrm{~K}$ gradually increased the recrystallized grain size to $5.1 \mu \mathrm{m}$. Then, the recrystallized grain size considerably increased to $10.5 \mu \mathrm{m}$ upon further increase in temperature to $1373 \mathrm{~K}$.

Features of the annealed microstructures were supplementary studied using TEM. The partially recrystallized microstructure that developed during annealing at $973 \mathrm{~K}$ is shown in Fig. 5a. The upper portion of the TEM image in Fig. 5a shows a typical work hardened microstructure (compare with Fig. 1), whereas the lower portion corresponds to a recrystallized grain. It is worth noting that numerous dispersed particles are clearly seen in the recrystallized microstructure (Fig. 5a). These particles formed a kind of chains aligned with highly
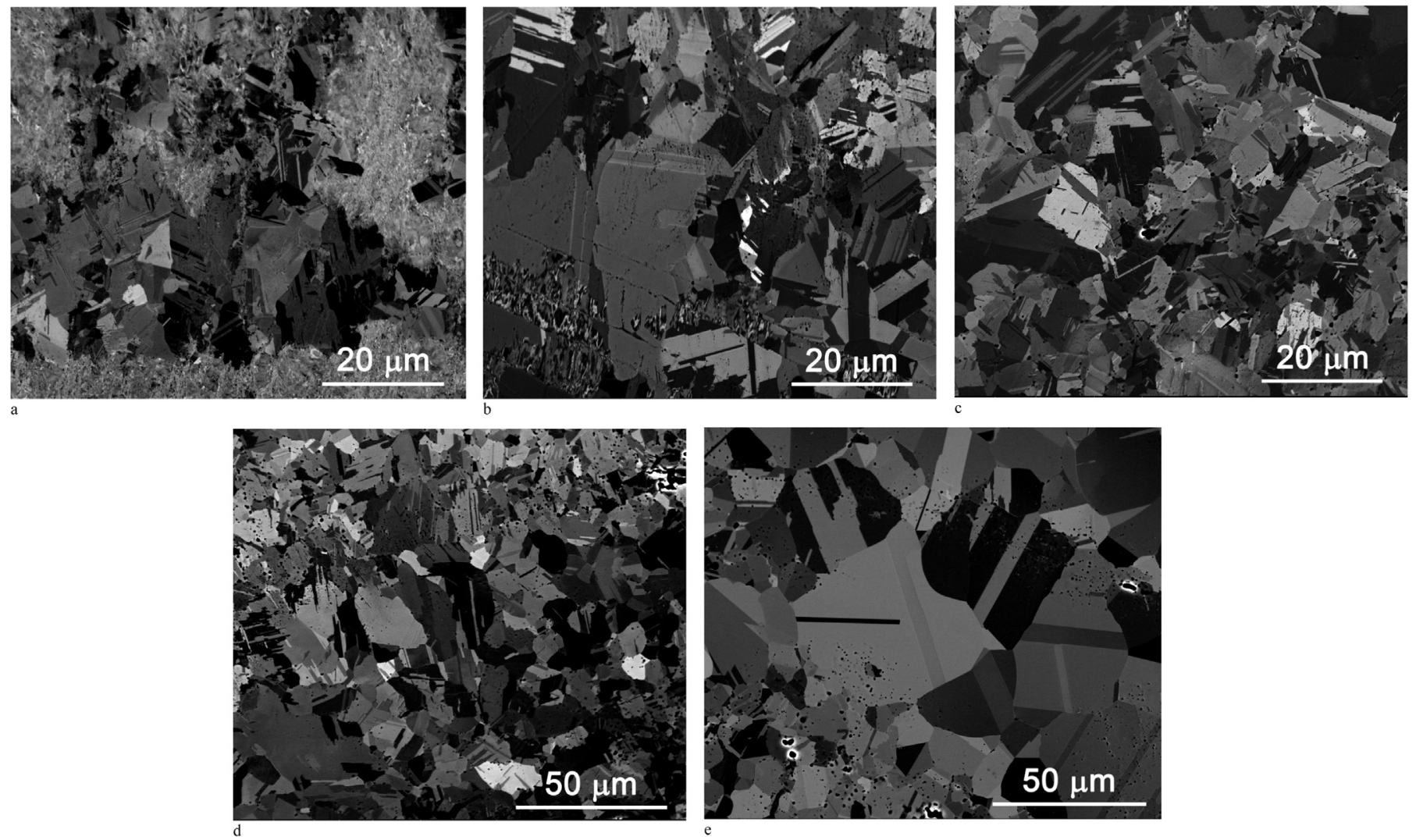

Fig. 3. Microstructure of the C-containing CoCrFeNiMn-type alloy after annealing at $973 \mathrm{~K}$ (a); $1073 \mathrm{~K}$ (b); $1173 \mathrm{~K}$ (c); $1273 \mathrm{~K}$ (d) or $1373 \mathrm{~K}$ (e) for $1 \mathrm{~h}$. 

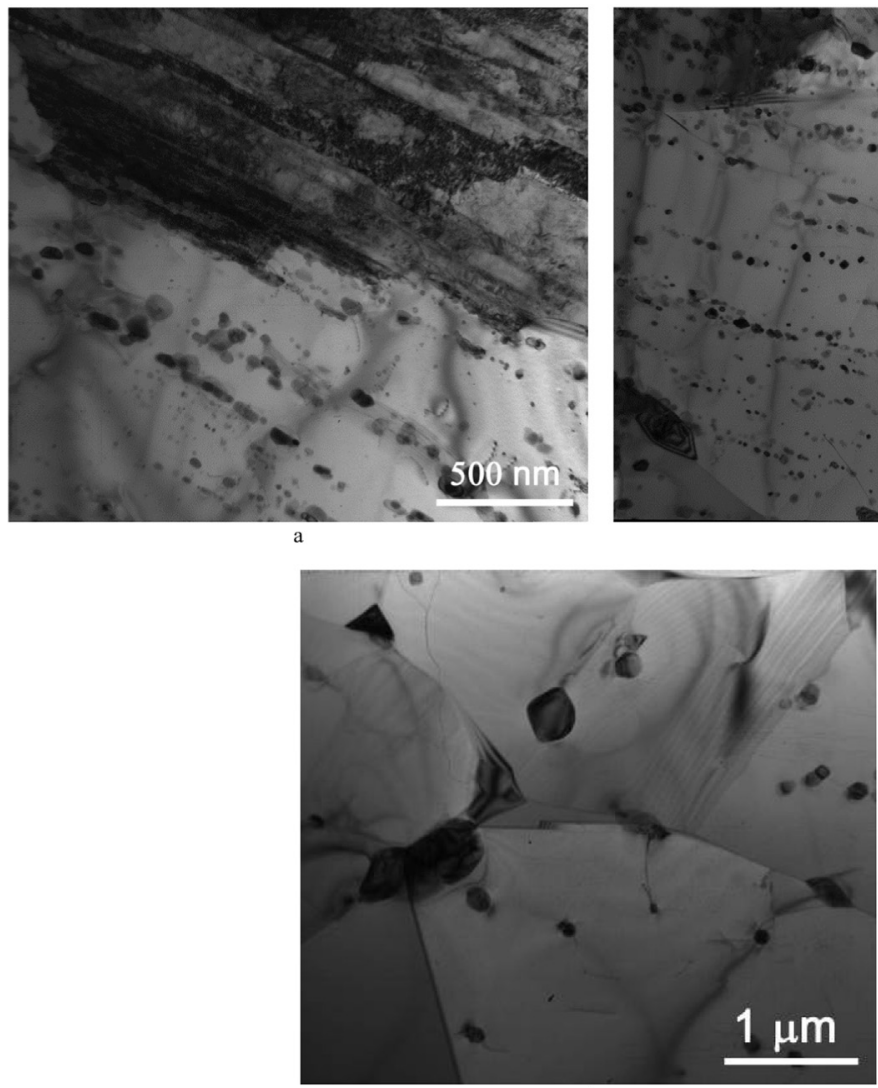
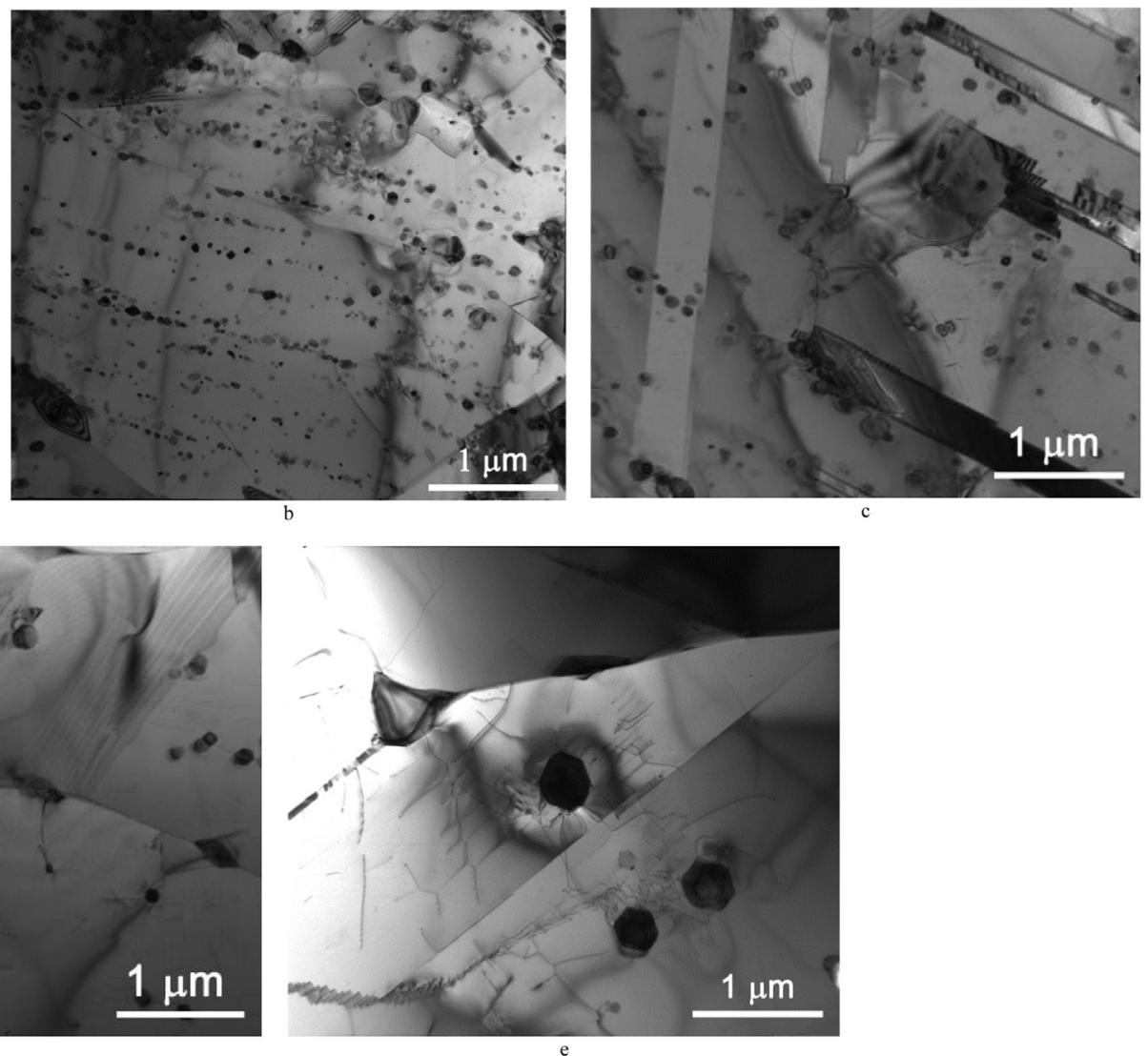

Fig. 5. TEM microstructure of the C-containing CoCrFeNiMn-type alloy after annealing at $973 \mathrm{~K}$ (a); $1073 \mathrm{~K}$ (b); $1173 \mathrm{~K}$ (c); $1273 \mathrm{~K}$ (d) or $1373 \mathrm{~K}$ (e) for 1 h.

elongated grains/subgrains. The distance between these particle chains was $\sim 220 \mathrm{~nm}$ almost coinciding with the transverse grain/subgrain size in the cold rolled microstructure. The particle size increased and the number of particles decreased with an increase in the annealing temperature (Fig. 5b to e). However, this chain-like arrangement of the particles was not observed anymore after annealing at $1273 \mathrm{~K}$ or $1373 \mathrm{~K}$ (Fig. 5d and e).

A series of X-ray diffraction curves (Fig. 6) suggested that the alloy after annealing consisted of an fcc matrix phase with a lattice parameter of $0.358 \mathrm{~nm}$ and $\mathrm{M}_{23} \mathrm{C}_{6}$-type carbides with a lattice parameter of $1.059 \mathrm{~nm}$. The selected area electron diffraction in TEM confirmed that the dispersed particles were $\mathrm{M}_{23} \mathrm{C}_{6}$-type carbides (Fig. 7). Local TEMEDS analysis has revealed that the $\mathrm{M}_{23} \mathrm{C}_{6}$ carbides were mostly

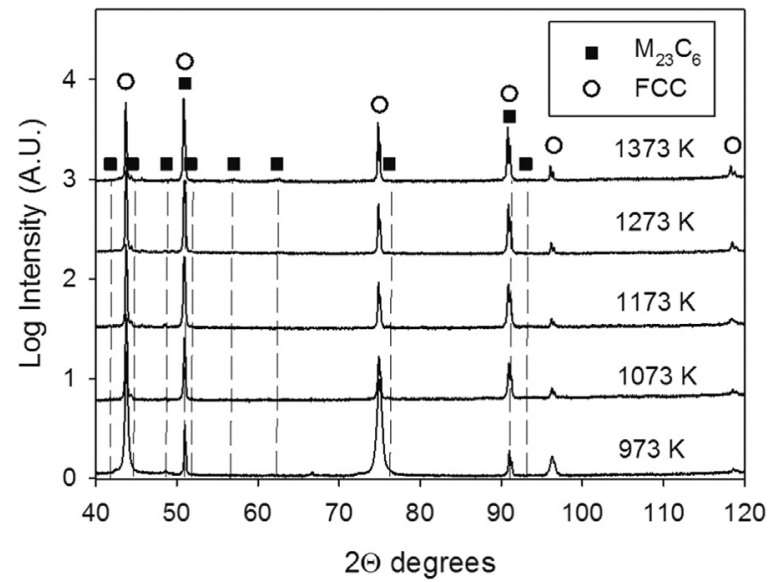

Fig. 6. XRD patterns of the cold-rolled C-containing CoCrFeNiMn-type alloy after annealing at $973-1373 \mathrm{~K}$ for $1 \mathrm{~h}$. composed of $\mathrm{Cr}(\sim 60$ at\%), and also contained a large amount of $\mathrm{Fe}$ and $\mathrm{Ni}(\sim 11-16$ at\% each). Because the energy resolution of the TEMEDS system used in the current study was insufficient to quantify the concentration of carbon reliably, only metallic elements were analyzed. The measured percentage of metallic elements in fcc matrix did not differ from the nominal composition of the alloy by more than \pm 2 at $\%$.

The carbide particle size and the volume fraction as functions of the annealing temperature are shown in Fig. 8. Carbide particle coarsening with increasing the annealing temperature correlated with the recrystallized grain growth. Namely, the particle size gradually increased from $34 \mathrm{~nm}$ to $80 \mathrm{~nm}$ with an increase in the temperature from $973 \mathrm{~K}$ to $1173 \mathrm{~K}$ followed by an accelerated growth to $320 \mathrm{~nm}$ as the temperature increased to $1373 \mathrm{~K}$. An increase in the annealing temperature was accompanied by a decrease in the volume fraction of carbide particles. Similar to the temperature dependency of the particle size, a weak temperature dependence of the particle volume fraction in the range of 973-1173 K, where the particle fraction decreased from 0.042 to 0.031 , becomes rather strong at higher temperatures leading to a remarkable decrease in the particle fraction to 0.014 after annealing at $1373 \mathrm{~K}$.

\subsubsection{Isothermal annealing}

Typical microstructures formed in the cold rolled alloy after annealing at $1173 \mathrm{~K}$ for $2-50 \mathrm{~h}$ are shown in Fig. 9. Annealing was accompanied by a pronounced grain growth. The mean grain size increased almost tenfold from $4.2 \mu \mathrm{m}$ to $41.5 \mu \mathrm{m}$ with an increase in the annealing time from $1-50 \mathrm{~h}$. A number of equilibrium triple junctions of grain boundaries in Fig. $9\left(120^{\circ}\right.$ between boundaries in triple junctions) are indicative of normal grain growth as the main mechanism of microstructure evolution. The growing grains in Fig. 9 are characterized by numerous annealing twins, which are typical of low SFE metals and alloys during recrystallization followed by normal grain growth [49]. The grain growth takes place concurrently with the carbide particle 

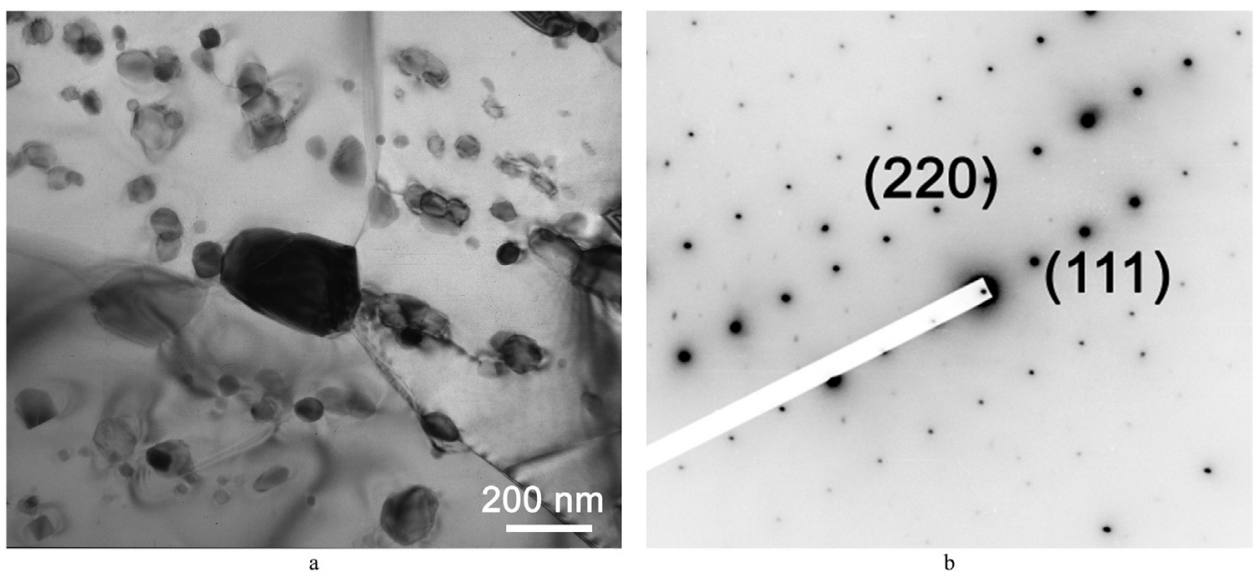

Fig. 7. TEM image of a $\mathrm{M}_{23} \mathrm{C}_{6}$-type carbide (a) and corresponding selected area electron diffraction pattern with the zone axis of [220] (b) after annealing of the Ccontaining CoCrFeNiMn-type alloy at $1073 \mathrm{~K}$ for $1 \mathrm{~h}$.

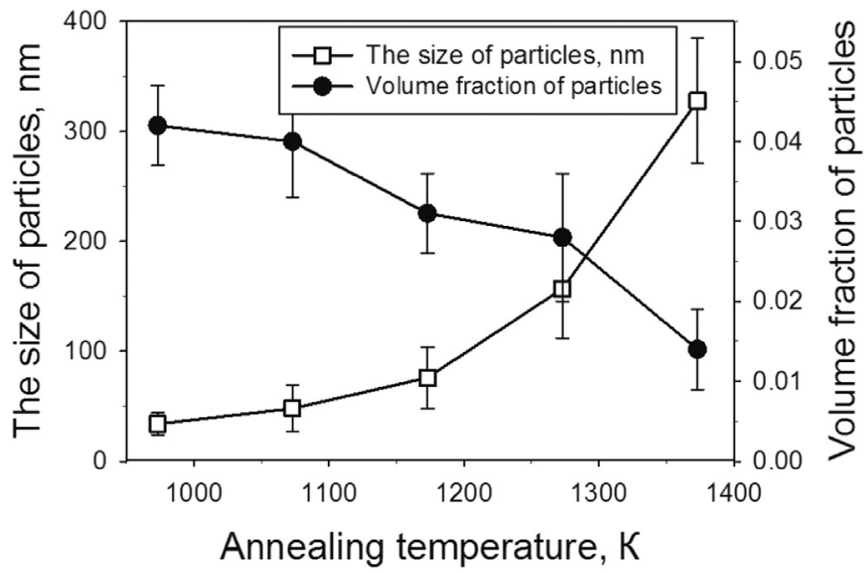

Fig. 8. Dependence of the size and volume fraction of carbide particles of the Ccontaining CoCrFeNiMn-type alloy on annealing temperature.

coarsening (Fig. 10). An increase in the annealing time from $1 \mathrm{~h}$ to $50 \mathrm{~h}$ increased the particle size from $80 \mathrm{~nm}$ to $465 \mathrm{~nm}$, but noticeable changes in the volume fraction of carbides were not found.

A power law function of annealing time, $d \sim t^{1 / n}$, is commonly used to express the grain/particle size [50]. The kinetics of fcc grain growth and carbide particle coarsening during annealing at $1173 \mathrm{~K}$ are represented in Fig. 11 in double logarithmic scale. It is clearly seen in Fig. 11 that the grain size and the carbide particle size can be related to annealing time with grain/particle growth exponents of about 2 and 3, respectively.

\subsection{Tensile tests}

\subsubsection{Stress-strain curves}

A series of tensile stress-strain curves for the program alloy subjected to cold rolling and annealing at various temperatures for $1 \mathrm{~h}$ is shown in Fig. 12; representative mechanical properties, i.e., yield strength $\left(\sigma_{0.2}\right)$, ultimate tensile strength (UTS), total elongation $(\delta)$, and uniform elongation $\left(\varepsilon_{\mathrm{u}}\right)$, are summarized in Table 2. After cold rolling, the alloy demonstrated high values of $\sigma_{0.2}$ and UTS (1310 MPa and $1500 \mathrm{MPa}$, respectively), however, the hardening capacity was quite limited. The flow stress rapidly increased to its maximum at quite small strain followed by necking and failure at total elongation of $6.5 \%$.

Annealing promoted the hardening ability and the tensile test behavior was characterized by a pronounced strain hardening stage, which expanded with an increase in the annealing temperature. The uniform elongation increased to $40 \%$ as the annealing temperature rose to $1373 \mathrm{~K}$. The enhancement of ductility after annealing was achieved at expense of strength. The yield strength of $870 \mathrm{MPa}$ and the ultimate tensile strength of $1060 \mathrm{MPa}$ were obtained after annealing at $973 \mathrm{~K}$. An increase in the annealing temperature resulted in further softening of the alloy. After annealing at $1373 \mathrm{~K}$, the yield strength and ultimate tensile strength were $320 \mathrm{MPa}$ and $760 \mathrm{MPa}$, respectively.

\subsubsection{Deformation substructures}

The tensile tests of the samples annealed at $1173 \mathrm{~K}$ for $1 \mathrm{~h}$ were interrupted at elongations of $5 \%$ and $22 \%$ to clarify operating deformation mechanisms. Dislocation substructures, which formed in the samples at different tensile strains, are shown in Fig. 13. A uniform dislocation distribution was observed at $5 \%$ strain (Fig. 13a). Dislocation tangles and pileups were seen in the vicinity of dispersed particles (indicated by arrows in Fig. 13a) inside grains and at grain boundaries. Further plastic deformation caused the formation of a microstructure with a high dislocation density, dense dislocation walls and deformation twins (Fig. 13b).

\section{Discussion}

The present work has demonstrated that the annealing at 973-1373 K of the cold-worked CoCrFeNiMn-type high-entropy alloy resulted in (i) recrystallization of the deformed fcc matrix and (ii) precipitation of the fine $\mathrm{Cr}$-rich $\mathrm{M}_{23} \mathrm{C}_{6}$-type carbides (Figs. 3-8). Recrystallization of the fcc solid solution after annealing in the examined temperature range can be readily anticipated taking into account available information on alloys with similar compositions $[20,38,42,51-53]$. However, some features of the carbide particles precipitation required additional consideration.

An equilibrium phase diagram for the present interstitial CoCrFeNiMn-type high-entropy alloy calculated by Thermo-Calc using the composition given in Table 1 is shown in Fig. 14a. After the solidification, the alloy is expected to have an fcc single phase structure, that is consistent with an experimentally obtained as-cast microstructure [39] and the program alloy structure after cold rolling (Fig. 1). The $\mathrm{M}_{23} \mathrm{C}_{6}$ carbides precipitation at temperatures below $\sim 1400 \mathrm{~K}$, predicted by simulation is also in excellent agreement with the obtained experimental data (Fig. 6). Therefore, the precipitation of carbides after annealing of the program alloy can be attributed to thermodynamic instability of the interstitial solid solution in the given temperature range.

The equilibrium phase diagram also suggested the precipitation of a $\mathrm{Ni}, \mathrm{Al}$ - rich $\mathrm{B} 2$ phase after annealing at temperatures below $\sim 1200 \mathrm{~K}$ and a $\mathrm{Cr}, \mathrm{Fe}-$ rich sigma-phase below $1000 \mathrm{~K}$ (Fig. 14a). But the experimental observations have not detected any signs of these phases 

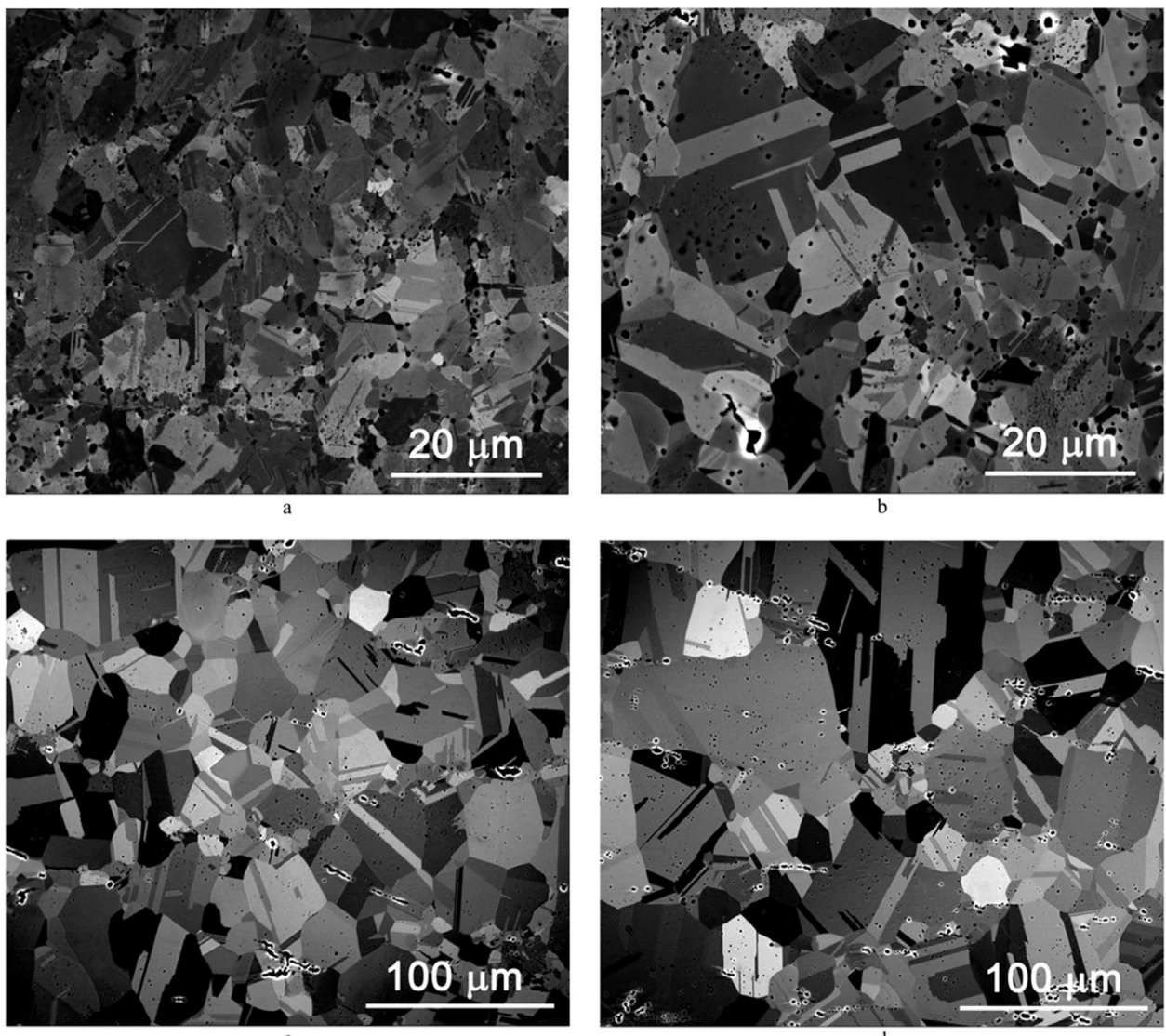

Fig. 9. Microstructure of the C-containing CoCrFeNiMn-type alloy alloys after annealing at $1173 \mathrm{~K} \mathrm{during}$ : $2 \mathrm{~h}$ (a); $5 \mathrm{~h} \mathrm{(b);} 10 \mathrm{~h}$ (c); $50 \mathrm{~h}$ (d).
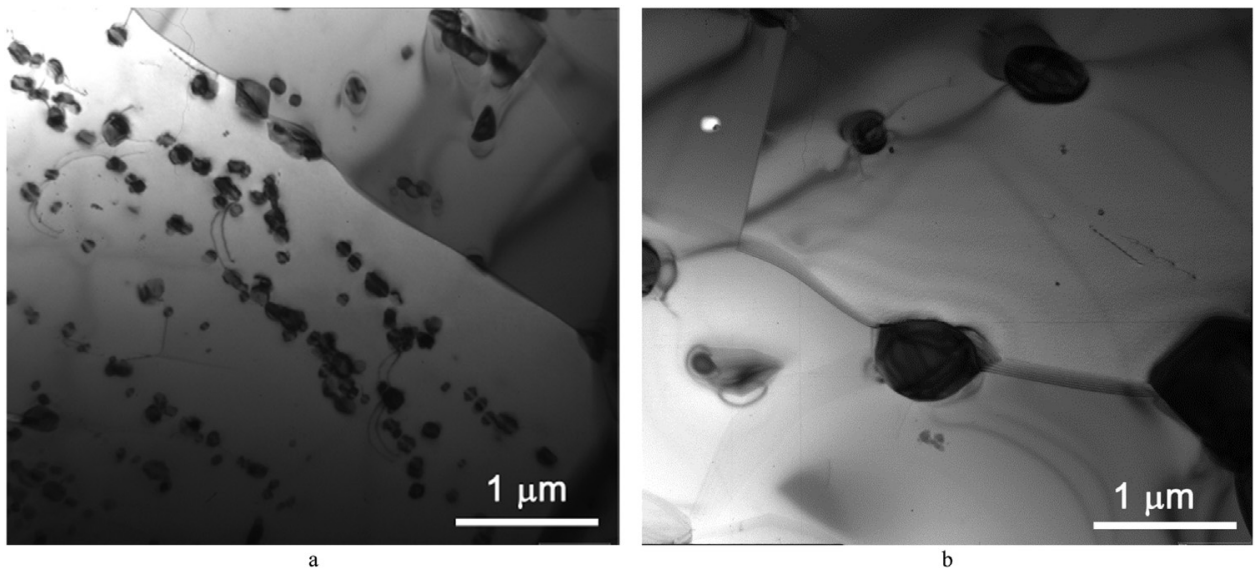

Fig. 10. TEM microstructure of the C-containing CoCrFeNiMn-type alloy alloys after annealing at $1173 \mathrm{~K} \mathrm{during}$ : $5 \mathrm{~h}$ (a); $50 \mathrm{~h}$ (b).

(Fig. 6). It might be hypothesized that the annealing time $(1 \mathrm{~h})$ at temperatures below $\sim 1200 \mathrm{~K}$ was insufficient to reach the equilibrium phase composition due to slow kinetics of the phase transformations. For instance, sigma phase precipitation kinetics in austenitic steels is known to be slow [54]. However, the B2 phase was not observed in the alloy even after annealing at $1173 \mathrm{~K}$ for $50 \mathrm{~h}$ (Fig. 10b). It is highly possible that the actual solvus temperature of the $\mathrm{B} 2$ phase is lower than the Termo-Calc predictions. The inaccuracy of the Termo-Calc calculations can be attributed to limitations of the available commercial databases [5].

The experimental values of $\mathrm{M}_{23} \mathrm{C}_{6}$-type carbide volume fractions, which were obtained by TEM investigations (Fig. 8), are compared with the equilibrium fractions by Thermo-Calc software in Fig. 14b. It is clearly seen that the experimental carbide volume fractions are close to the equilibrium ones and the same trend is observed for both dependencies; although the experimental values are somewhat higher. The latter can be attributed to some differences in the predicted (equilibrium) and experimental chemical compositions of the carbides. According to the Thermo-Calc prediction, the chemical composition of carbides is very close to $\mathrm{Cr}_{23} \mathrm{C}_{6}$, while TEM-EDS measurements have revealed the presence of a significant amount of other metallic elements such as $\mathrm{Co}$ and $\mathrm{Fe}$.

It is worth noting a non-random distribution of the carbides in the microstructure annealed at relatively low temperatures (973-1173 K). The particles formed a kind of chains along the lamellar-like grains and subgrains (Fig. 5a to c). Such an arrangement implies that the particles 


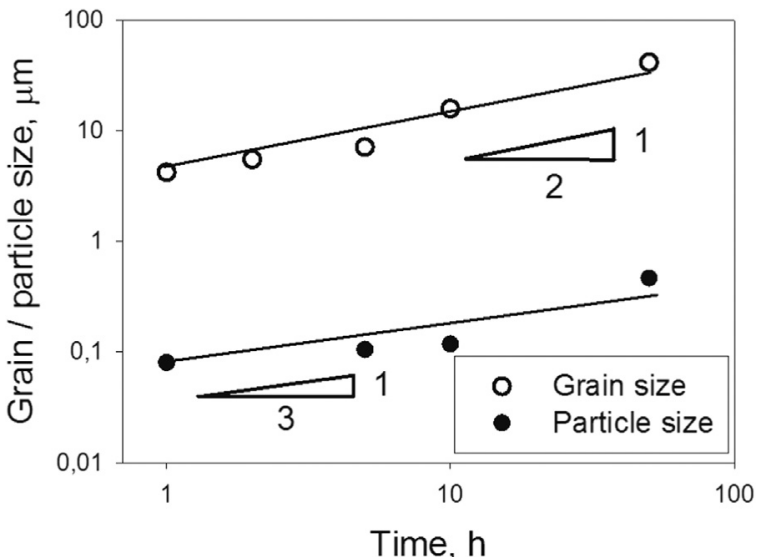

Fig. 11. Dependence of the fcc grain and carbide particle size on annealing time during annealing at $1173 \mathrm{~K}$.

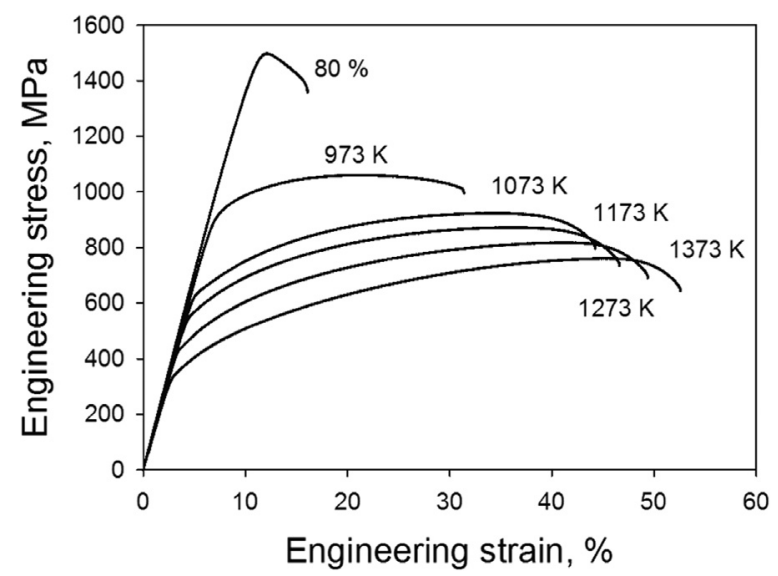

Fig. 12. Tensile stress-strain curves of the C-containing CoCrFeNiMn-type alloy after cold rolling and $1 \mathrm{~h}$ annealing at different temperatures.

Table 2

Tensile properties of the C-containing CoCrFeNiMn-type alloy in different conditions.

\begin{tabular}{lllll}
\hline Annealing temperature, $\mathrm{K}$ & $\sigma_{0.2}, \mathrm{MPa}$ & $\sigma_{\mathrm{UTS}}, \mathrm{MPa}$ & $\varepsilon_{\mathrm{u}}, \%$ & $\delta \%$ \\
\hline cold rolled & 1310 & 1500 & 3 & 6.5 \\
973 & 870 & 1060 & 13 & 24 \\
1073 & 610 & 925 & 25 & 38 \\
1173 & 530 & 875 & 27 & 41 \\
1273 & 435 & 820 & 36 & 44 \\
1373 & 320 & 760 & 40 & 47 \\
\hline
\end{tabular}

nucleated primarily at boundaries of the deformation-induced grains/ subgrains concurrently with recrystallization during annealing. At higher temperatures (1273 K or $1373 \mathrm{~K}$ ) this chain-like arrangement of the particles was not observed. Therefore, the particle distribution became random that can be associated with faster recrystallization kinetics in comparison with the kinetics of precipitating. In this case moving boundaries do not exist in the same place long enough for nucleation of a chain of the carbides. Similar character of the secondphase particles distribution was recently observed during annealing at different temperatures of a cold-worked HfNbTaTiZr alloy [55].

Dispersed particle coarsening is accepted to be controlled by volume diffusion if $n=3$ [56], or by diffusion along grain boundaries if $n=4$ [57]. The obtained results in Fig. 11 for the particle coarsening in the present alloy obey a power law function with an exponent of 3 , indicating on the volume diffusion as a coarsening controlling mechanism.
An interesting finding is associated with the fast kinetics of grain growth with a size exponent of $\mathrm{n}=2$ (Fig. 11). Although a grain growth exponent of $n=2$ has been suggested in an original theoretical analysis by Burke and Turnbull [58], such a relatively small value of the size exponent has been experimentally obtained for pure metals subjected to annealing at temperatures close to the melting point mainly [59]. The majority of experimental results have suggested much larger $\mathrm{n}$ of 3-10 for conventional structural alloys [60].

In case of high-entropy alloys, Wu et al. obtained $n \approx 4$ for various equiatomic alloys of Fe-Ni-Co-Cr-Mn system annealed at $1173 \mathrm{~K}$ [48]. A similar result $(\mathrm{n} \approx 3.5)$ was obtained by Juan et al. [61] during annealing of the HfNbTaTiZr alloy at temperatures between $1473 \mathrm{~K}$ and $1623 \mathrm{~K}$. However, in [55] the value of $\mathrm{n}$ was found to be 2 or 3 (both values describe the experimental data equally well) for the same HfNbTaTiZr alloy during annealing at $1373 \mathrm{~K}$. A more-commonly observed value of $n=3$ is generally associated with the drag of secondphase precipitates or the segregation of low-solubility alloying elements/impurities to grain boundaries. However, the absence of any second phases in HfNbTaTiZr above $1273 \mathrm{~K}$ caused the occurrence of normal grain growth with $n=2$, which is generally related to normal grain growth in pure systems or solid solutions with high mutual solubility of alloying elements [55]. The grain growth faster than the particle coarsening has been reported for ultrafine grained oxidebearing iron at elevated temperatures [62]. The faster grain growth kinetics may result from some kind of thermally activated unpinning of grain boundaries that has been found to become significant at high temperatures [63], although this interesting phenomena deserves further detailed investigation.

Analysis of mechanical properties of the program alloy after cold rolling and subsequent annealing shows that a proper thermo-mechanical treatment can provide quite an attractive strength/ductility balance (Fig. 12, Table 2). Commonly, the yield strength of particlebearing alloys is evaluated by a summation of the grain size strengthening and the particle strengthening. The grain size strengthening $\left(\sigma_{\mathrm{D}}\right)$ can be expressed by the second term of Hall-Petch-type relationship, which reads as follows [64].

$\sigma_{H-P}=\sigma_{0}+\mathrm{k} \mathrm{D}^{-0.5}$

where $\sigma_{0}$ is the Pieirls stress, D is the mean grain size (Fig. 4), and k is a numerical factor. The values of $\sigma_{0}=125 \mathrm{MPa}$ and $\mathrm{k}=0.494 \mathrm{MPa} \mathrm{m}^{0.5}$ have been reported for the yield strength calculation of a similar single phase CoCrFeNiMn high-entropy alloy [22]. Note here that the relatively large value of $\sigma_{0}$ obtained in previous experiments can be attributed to several unconsidered strengthening contributions, such as solid solution, impurities, annealed dislocation density, etc. Strengthening by relatively large non-shearable particles is usually related to the Orowan mechanism of dislocation looping [65]:

$\sigma_{\text {Or }}=\left(0.538 \mathrm{G} \mathrm{b} \mathrm{f}^{1 / 2} \mathrm{~d}\right) \ln (\mathrm{d} / 2 \mathrm{~b})$

Here, $\mathrm{G}=80 \mathrm{GPa}$ is the shear modulus [26], $\mathrm{b}=2.58 \times 10^{-10}$ $\mathrm{m}^{-10}$ is the Burgers vector [23], $\mathrm{f}$ and $\mathrm{d}$ are the fraction and size of the precipitates (Fig. 8), respectively.

A comparison between the experimental yield strength obtained by tensile tests (Table 2) and that calculated by Eqs. (1) and (2) is presented in Fig. 15. It is clearly seen that the calculated values match well the experimental ones for all annealed samples except those annealed at $973 \mathrm{~K}$. These samples exhibit the yield strength, which is remarkably higher than the calculated one. It should be noted that these samples with the highest yield strength among all annealed samples were annealed at the lowest temperature. Besides the finer recrystallized grains, the samples annealed at a relatively low temperature of $973 \mathrm{~K}$ were characterized by a rather large non-recrystallized fraction of about 0.4 (Fig. 4). The difference of about $150 \mathrm{MPa}$ between the experimental and calculated yield strengths, therefore, can be attributed to an additional contribution of the remnants of work hardened grains to the overall strength. 

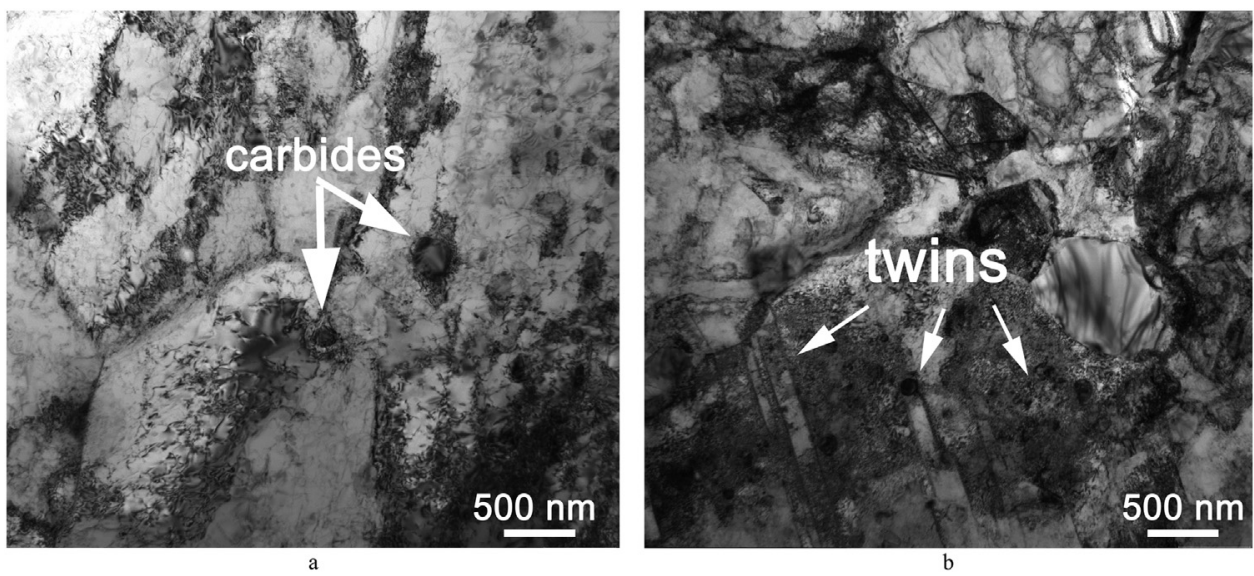

Fig. 13. Microstructure of the C-containing CoCrFeNiMn-type alloy after $1 \mathrm{~h}$ annealing at $1173 \mathrm{~K}$ and room temperature tension to $5 \%$ (a) and $22 \%$ (b).

Among all strengthening contributions shown in Fig. 15 for the present alloy subjected to cold rolling followed by annealing at 973-1373 K, the highest strength increment is provided by the grain refinement $\left(\sigma_{\mathrm{D}}\right)$. Even in the case of the coarse grain microstructure evolved after annealing at high temperatures, the grain size strengthening is higher than $\sigma_{0}$. A decrease in the annealing temperature results in a decrease in both the grain size and the particle size. Therefore, the strengthening from the grain refinement is accompanied by the dispersion strengthening $\left(\sigma_{\mathrm{Or}}\right)$. The latter is quite small after annealing at temperatures above $1273 \mathrm{~K}$, however, $\sigma_{\mathrm{Or}}$ increases remarkably and exceeds $\sigma_{0}$ after annealing at temperatures below $1173 \mathrm{~K}$. After annealing at relatively low temperature of $973 \mathrm{~K}$, the finely dispersed carbides provide significant strengthening, which is comparable with that from the grain refinement.

Note that some individual twins were observed in the tensile tested specimen after straining to $22 \%$ (Fig. 13b). This finding is in agreement with the available information on the evolution of microstructure of the program alloy during rolling [39], when twinning initiated after $20 \%$ thickness reduction. However, one must keep in mind that the alloy was subjected to cold rolling in a single phase as-cast condition, i.e. all available carbon $(0.69$ at $\%)$ was in solid solution. In turn, after annealing carbon strongly partitioned to carbide particles. Although corresponding experimental data is unavailable, Thermo-Calc calculations suggest the equilibrium carbon content in fcc matrix of $\sim 0.14$ at $\%$ at $1173 \mathrm{~K}$. Further studies are required to evaluate precisely the effect of the solute carbon amount on deformation mechanisms of the fccstructured HEAs; nevertheless it can be supposed that deformation

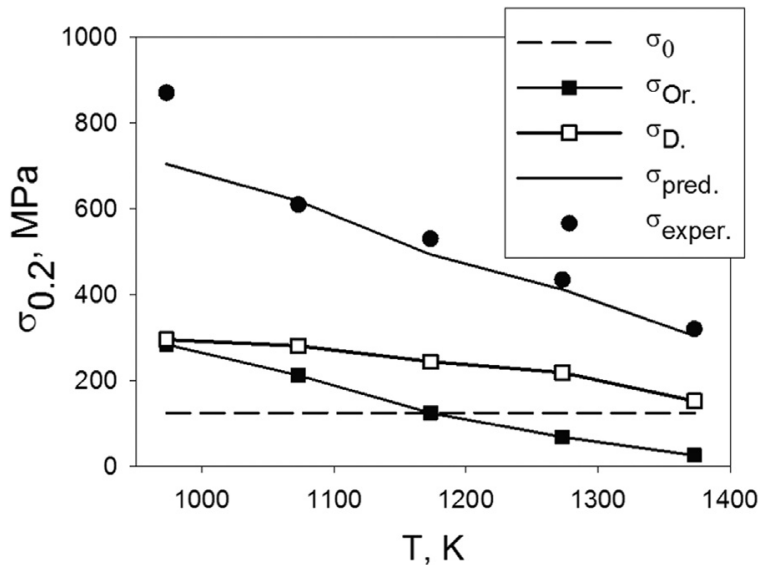

Fig. 15. Yield strength of the C-containing CoCrFeNiMn-type alloy with different grain size and particle dispersion depending on annealing temperature.

twinning is responsible for a homogeneous increase in the dislocation density, resulting in large strain hardening stage, which suppresses necking and promotes uniform elongation during tensile tests of the annealed alloy (Fig. 12, Table 2), similar to twinning-induced plasticity steels [66].
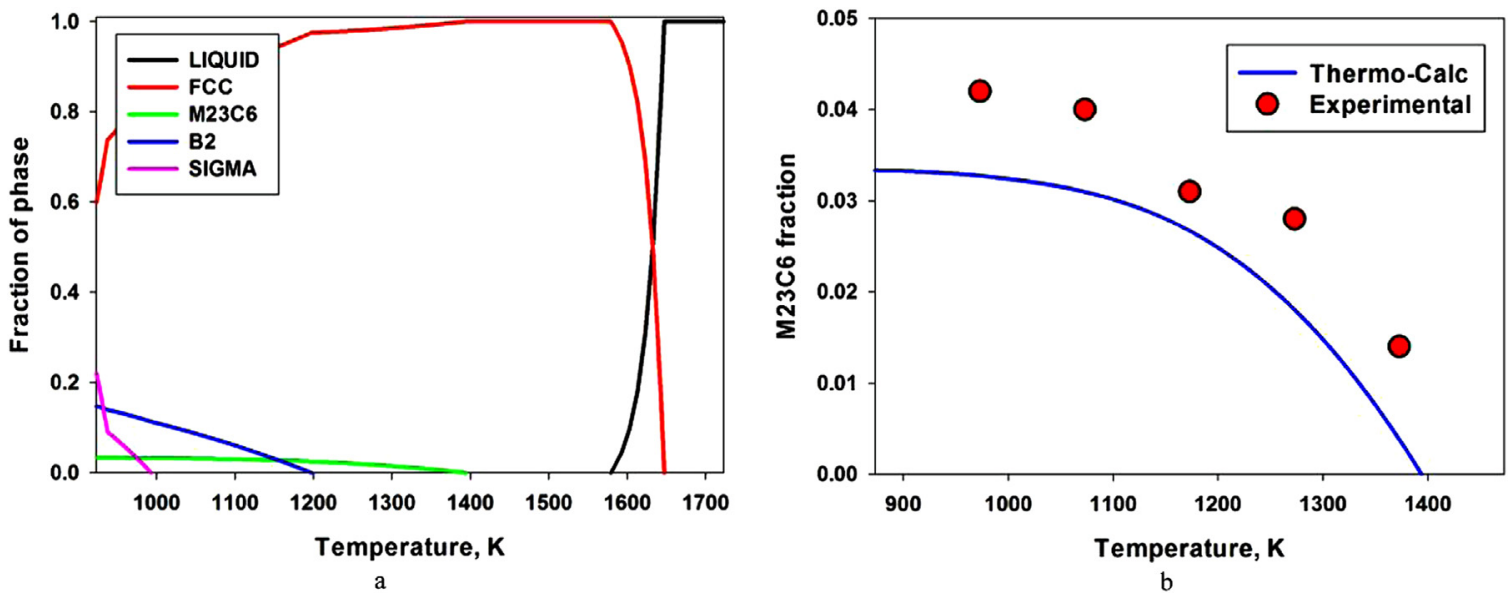

Fig. 14. Thermo-Calc predictions of the equilibrium phase composition of the program alloy: dependence of the fraction of equilibrium phases on temperature (a) and dependence of the equilibrium fraction of $\mathrm{M}_{23} \mathrm{C}_{6}$ carbides in comparison with the experimental data (b). 


\section{Conclusions}

The microstructure and mechanical properties of a C-containing CoCrFeNiMn high-entropy alloy subjected to cold rolling followed by annealing at $973-1373 \mathrm{~K}$ were studied. The main results can be summarized as follows:

1. Annealing was accompanied by (i) recrystallization of an fcc matrix and (ii) an $\mathrm{M}_{23} \mathrm{C}_{6}$-type carbide precipitation. Fully recrystallized microstructures evolved after $1 \mathrm{~h}$ annealing at temperatures above $1073 \mathrm{~K}$. The fcc grain size increased from $2.8 \mu \mathrm{m}$ to $10.5 \mu \mathrm{m}$ with an increase in the annealing temperature from $973 \mathrm{~K}$ to $1373 \mathrm{~K}$. The size of the carbides increased from $34 \mathrm{~nm}$ to $320 \mathrm{~nm}$, and their volume fraction decreased from about $0.04-0.015$ with an increase in the annealing temperature from $973 \mathrm{~K}$ to $1373 \mathrm{~K}$. The carbide fraction was in reasonable agreement with the equilibrium fraction predicted by Thermo-Calc.

2. Following primary recrystallization, normal grain was accompanied by a rapid coarsening of the carbide particles. An increase in the annealing time from $1 \mathrm{~h}$ to $50 \mathrm{~h}$ at $1173 \mathrm{~K}$ resulted in an increase of the fcc grain size from $4.2 \mu \mathrm{m}$ to $41.5 \mu \mathrm{m}$ and in an increase of the size of carbides from $80 \mathrm{~nm}$ to $465 \mathrm{~nm}$. The fraction of carbides did not change noticeably. The grain growth and particle coarsening can be expressed by power law functions of annealing time with grain/ particle size exponents of about 2 and 3, respectively.

3. Cold rolling significantly strengthened the alloy, resulting in the yield strength as high as $1310 \mathrm{MPa}$. An increase in the annealing temperature from $973 \mathrm{~K}$ to $1373 \mathrm{~K}$ led to a gradual softening; the yield strength correspondingly decreased from $870 \mathrm{MPa}$ to $320 \mathrm{MPa}$, whereas the total elongation increased from $24 \%$ to $47 \%$.

4. The grain size strengthening is a major contributor to the overall strength. A decrease in the grain and particle sizes with a decrease in the annealing temperature enhanced both the grain size strengthening and the dispersion strengthening, which was quite small after annealing at temperatures above $1273 \mathrm{~K}$ but became comparable with the grain size strengthening after annealing at $973 \mathrm{~K}$.

\section{Acknowledgements}

This work was supported by Russian Foundation for Basic Research, Russia (grant No16-38-60061). The authors are also grateful to the personnel of the Joint Research Center, "Technology and Materials", Belgorod State National Research University, for their assistance with the instrumental analysis.

\section{References}

1] J.-W. Yeh, S.-K. Chen, S.-J. Lin, J.-Y. Gan, T.-S. Chin, T.-T. Shun, C.-H. Tsau, S.Y. Chang, Nanostructured high-entropy alloys with multiple principal elements: novel alloy design concepts and outcomes, Adv. Eng. Mater. 6 (2004) 299-303, https://doi.org/10.1002/adem.200300567.

[2] Y. Zhang, T.T. Zuo, Z. Tang, M.C. Gao, K.A. Dahmen, P.K. Liaw, Z.P. Lu, Microstructures and properties of high-entropy alloys, Prog. Mater. Sci. 61 (2014), https://doi.org/10.1016/j.pmatsci.2013.10.001.

[3] D.B. Miracle, O.N. Senkov, A critical review of high entropy alloys and related concepts, Acta Mater. 122 (2017) 448-511, https://doi.org/10.1016/j.actamat 2016.08.081.

[4] S. Gorsse, D.B. Miracle, O.N. Senkov, Mapping the world of complex concentrated alloys, Acta Mater. 135 (2017) 177-187, https://doi.org/10.1016/j.actamat.2017. 06.027.

[5] O.N. Senkov, D.B. Miracle, K.J. Chaput, J.-P. Couzinie, Development and exploration of refractory high entropy alloys-a review, J. Mater. Res. (2018) 1-37, https://doi.org/10.1557/jmr.2018.153.

[6] O.N. Senkov, J.K. Jensen, A.L. Pilchak, D.B. Miracle, H.L. Fraser, Compositional variation effects on the microstructure and properties of a refractory high-entropy superalloy AlMo0.5NbTa0.5TiZr, Mater. Des. 139 (2018) 498-511, https://doi.org/ 10.1016/j.matdes.2017.11.033.

[7] O.N. Senkov, S. Rao, K.J. Chaput, C. Woodward, Compositional effect on microstructure and properties of NbTiZr-based complex concentrated alloys, Acta Mater. 151 (2018) 201-215, https://doi.org/10.1016/j.actamat.2018.03.065.

[8] Z. Li, K.G. Pradeep, Y. Deng, D. Raabe, C.C. Tasan, Metastable high-entropy dual- phase alloys overcome the strength-ductility trade-off, Nature 534 (2016), https:// doi.org/10.1038/nature17981.

[9] Z. Li, C.C. Tasan, H. Springer, B. Gault, D. Raabe, Interstitial atoms enable joint twinning and transformation induced plasticity in strong and ductile high-entropy alloys, Sci. Rep. 7 (2017) 1-7, https://doi.org/10.1038/srep40704.

[10] J.Y. He, H. Wang, H.L. Huang, X.D. Xu, M.W. Chen, Y. Wu, X.J. Liu, T.G. Nieh, K. An, Z.P. Lu, A precipitation-hardened high-entropy alloy with outstanding tensile properties, Acta Mater. 102 (2016) 187-196, https://doi.org/10.1016/j.actamat. 2015.08.076.

[11] N.Y. Yurchenko, N.D. Stepanov, D.G. Shaysultanov, M.A. Tikhonovsky, G.A. Salishchev, Effect of Al content on structure and mechanical properties of the AlxCrNbTiVZr (x?? = ??0; 0.25; 0.5; 1 ) high-entropy alloys, Mater. Charact. 121 (2016) 125-134, https://doi.org/10.1016/j.matchar.2016.09.039.

[12] B. Gludovatz, A. Hohenwarter, D. Catoor, E.H. Chang, E.P. George, R.O. Ritchie, A fracture-resistant high-entropy alloy for cryogenic applications, Science. (80-.) 345 (2014) 1153-1158, https://doi.org/10.1126/science.1254581.

[13] Z. Zhang, M.M. Mao, J. Wang, B. Gludovatz, Z. Zhang, S.X. Mao, E.P. George, Q. Yu, R.O. Ritchie, Nanoscale origins of the damage tolerance of the high-entropy alloy CrMnFeCoNi, Nat. Commun. 6 (2015) 10143, https://doi.org/10.1038/ ncomms10143.

[14] N.D. Stepanov, D.G. Shaysultanov, R.S. Chernichenko, D.M. Ikornikov, V.N. Sanin, S.V. Zherebtsov, Mechanical properties of a new high entropy alloy with a duplex ultra-fine grained structure, Mater. Sci. Eng. A 728 (2018), https://doi.org/10. 1016/j.msea.2018.04.118.

[15] B. Cantor, I.T.H. Chang, P. Knight, A.J.B. Vincent, Microstructural development in equiatomic multicomponent alloys, Mater. Sci. Eng. A 375-377 (2004) 213-218, https://doi.org/10.1016/j.msea.2003.10.257.

[16] F. Otto, Y. Yang, H. Bei, E.P.P. George, Relative effects of enthalpy and entropy on the phase stability of equiatomic high-entropy alloys, Acta Mater. 61 (2013) 2628-2638, https://doi.org/10.1016/j.actamat.2013.01.042.

[17] E.J. Pickering, R. Muñoz-Moreno, H.J. Stone, N.G. Jones, Precipitation in the equiatomic high-entropy alloy CrMnFeCoNi, Scr. Mater. 113 (2016), https://doi org/10.1016/j.scriptamat.2015.10.025.

[18] F. Otto, A. Dlouhý, K.G. Pradeep, M. Kuběnová, D. Raabe, G. Eggeler, E.P. George, Decomposition of the single-phase high-entropy alloy CrMnFeCoNi after prolonged anneals at intermediate temperatures, Acta Mater. 112 (2016) 40-52, https://doi. org/10.1016/j.actamat.2016.04.005.

[19] B. Schuh, F. Mendez-Martin, B. Völker, E.P. George, H. Clemens, R. Pippan, A. Hohenwarter, Mechanical properties, microstructure and thermal stability of a nanocrystalline CoCrFeMnNi high-entropy alloy after severe plastic deformation, Acta Mater. 96 (2015) 258-268, https://doi.org/10.1016/j.actamat.2015.06.025.

[20] N.D. Stepanov, D.G. Shaysultanov, M.S. Ozerov, S.V. Zherebtsov, G.A. Salishchev, Second phase formation in the CoCrFeNiMn high entropy alloy after recrystallization annealing, Mater. Lett. 185 (2016) 1-4, https://doi.org/10.1016/j.matlet. 2016.08.088.

[21] A. Gali, E.P. George, Tensile properties of high- and medium-entropy alloys, Intermetallics 39 (2013) 74-78, https://doi.org/10.1016/j.intermet.2013.03.018.

[22] F. Otto, A. Dlouhý, C. Somsen, H. Bei, G. Eggeler, E.P. George, The influences of temperature and microstructure on the tensile properties of a CoCrFeMnNi highentropy alloy, Acta Mater. 61 (2013) 5743-5755, https://doi.org/10.1016/j actamat.2013.06.018.

[23] N. Stepanov, M. Tikhonovsky, N. Yurchenko, D. Zyabkin, M. Klimova, S. Zherebtsov, A. Efimov, G. Salishchev, Effect of cryo-deformation on structure and properties of CoCrFeNiMn high-entropy alloy, Intermetallics 59 (2015) 8-17, https://doi.org/10.1016/j.intermet.2014.12.004.

[24] G. Laplanche, A. Kostka, O.M. Horst, G. Eggeler, E.P. George, Microstructure evolution and critical stress for twinning in the CrMnFeCoNi high-entropy alloy, Acta Mater. 118 (2016) 152-163, https://doi.org/10.1016/j.actamat.2016.07.038.

[25] S.-H. Joo, H. Kato, M.J. Jang, J. Moon, C.W. Tsai, J.W. Yeh, H.S. Kim, Tensile deformation behavior and deformation twinning of an equimolar CoCrFeMnNi high-entropy alloy, Mater. Sci. Eng. A 689 (2017) 122-133, https://doi.org/10. 1016/j.msea.2017.02.043.

[26] Z. Wu, H. Bei, G.M. Pharr, E.P. George, Temperature dependence of the mechanical properties of equiatomic solid solution alloys with face-centered cubic crystal structures, Acta Mater. 81 (2014), https://doi.org/10.1016/j.actamat.2014.08.026.

[27] J.Y. He, H. Wang, Y. Wu, X.J. Liu, H.H. Mao, T.G. Nieh, Z.P. Lu, Precipitation behavior and its effects on tensile properties of FeCoNiCr high-entropy alloys, Intermetallics 79 (2016) 41-52, https://doi.org/10.1016/j.intermet.2016.09.005.

[28] K. Ming, X. Bi, J. Wang, Realizing strength-ductility combination of coarse-grained Al0.2Co1.5CrFeNi1.5Ti0.3alloy via nano-sized, coherent precipitates, Int. J. Plast. 100 (2018) 177-191, https://doi.org/10.1016/j.ijplas.2017.10.005.

[29] B. Gwalani, V. Soni, M. Lee, S. Mantri, Y. Ren, R. Banerjee, Optimizing the coupled effects of Hall-Petch and precipitation strengthening in a Al0.3CoCrFeNi high entropy alloy, Mater. Des. 121 (2017) 254-260, https://doi.org/10.1016/j.matdes. 2017.02.072.

[30] B. Gwalani, S. Gorsse, D. Choudhuri, M. Styles, Y. Zheng, R.S. Mishra, R. Banerjee, Modifying transformation pathways in high entropy alloys or complex concentrated alloys via thermo-mechanical processing, Acta Mater. 153 (2018) 169-185, https:// doi.org/10.1016/J.ACTAMAT.2018.05.009.

[31] D. Choudhuri, S. Shukla, W.B. Green, B. Gwalani, V. Ageh, R. Banerjee, R.S. Mishra, Crystallographically degenerate B2 precipitation in a plastically deformed fcc -based complex concentrated alloy, Mater. Res. Lett. 6 (2018) 171-177, https://doi. org $/ 10.1080 / 21663831.2018 .1426649$.

[32] N. Kashaev, V. Ventzke, N. Stepanov, D. Shaysultanov, V. Sanin, S. Zherebtsov, Laser beam welding of a CoCrFeNiMn-type high entropy alloy produced by selfpropagating high-temperature synthesis, Intermetallics 96 (2018) 63-71, https:// 
doi.org/10.1016/j.intermet.2018.02.014.

[33] H.Y. Yasuda, H. Miyamoto, K. Cho, T. Nagase, Formation of ultrafine-grained microstructure in Al0.3CoCrFeNi high entropy alloys with grain boundary precipitates, Mater. Lett. 199 (2017) 120-123, https://doi.org/10.1016/J.MATLET. 2017.04.072.

[34] W.H. Liu, T. Yang, C.T. Liu, Precipitation hardening in CoCrFeNi-based high entropy alloys, Mater. Chem. Phys. (2017), https://doi.org/10.1016/j.matchemphys. 2017.07.037.

[35] N.D. Stepanov, N.Y. Yurchenko, M.A. Tikhonovsky, G.A. Salishchev, Effect of carbon content and annealing on structure and hardness of the CoCrFeNiMn-based high entropy alloys, J. Alloy. Compd. 687 (2016) 59-71, https://doi.org/10.1016/j. jallcom.2016.06.103.

[36] J.Y. Ko, S.I. Hong, Microstructural evolution and mechanical performance of carbon-containing CoCrFeMnNi-C high entropy alloys, J. Alloy. Compd. 743 (2018) 115-125, https://doi.org/10.1016/j.jallcom.2018.01.348.

[37] L.B. Chen, R. Wei, K. Tang, J. Zhang, F. Jiang, L. He, J. Sun, Heavy carbon alloyed FCC-structured high entropy alloy with excellent combination of strength and ductility, Mater. Sci. Eng. A (2018), https://doi.org/10.1016/j.msea.2018.01.045.

[38] N.D. Stepanov, D.G. Shaysultanov, R.S. Chernichenko, N.Y. Yurchenko, S.V. Zherebtsov, M.A. Tikhonovsky, G.A. Salishchev, Effect of thermomechanical processing on microstructure and mechanical properties of the carbon-containing CoCrFeNiMn high entropy alloy, J. Alloy. Compd. 693 (2017) 394-405, https://doi. org/10.1016/j.jallcom.2016.09.208.

[39] M. Klimova, N. Stepanov, D. Shaysultanov, R. Chernichenko, N. Yurchenko, V. Sanin, S. Zherebtsov, Microstructure and mechanical properties evolution of the $\mathrm{Al}, \mathrm{C}$-containing CoCrFeNiMn-type high-entropy alloy during cold rolling, Materials (Basel) 11 (2017) 53, https://doi.org/10.3390/ma11010053.

[40] Z. Wang, I. Baker, Interstitial strengthening of a f.c.c. FeNiMnAlCr high entropy alloy, Mater. Lett. 180 (2016), https://doi.org/10.1016/j.matlet.2016.05.122.

[41] Z. Wang, I. Baker, Z. Cai, S. Chen, J.D. Poplawsky, The effect of interstitial carbon on the mechanical properties and dislocation substructure evolution in Fe40.4Ni11.3Mn34.8Al7.5Cr6and entropy alloys, Acta Mater. 120 (2016) 228-239, https://doi.org/10.1016/j.actamat.2016.08.072.

[42] Z. Wang, I. Baker, W. Guo, J.D. Poplawsky, The effect of carbon on the microstructures, mechanical properties, and deformation mechanisms of thermo-mechanically treated Fe40.4Ni11.3Mn34.8Al7.5Cr6 high entropy alloys, Acta Mater. 126 (2017) 346-360, https://doi.org/10.1016/j.actamat.2016.12.074.

[43] M. Wang, Z. Li, D. Raabe, In-situ SEM observation of phase transformation and twinning mechanisms in an interstitial high-entropy alloy, Acta Mater. 147 (2018) 236-246, https://doi.org/10.1016/j.actamat.2018.01.036.

[44] Z. Wu, C.M. Parish, H. Bei, Nano-twin mediated plasticity in carbon-containing FeNiCoCrMn high entropy alloys, J. Alloy. Compd. 647 (2015) 815-822, https:// doi.org/10.1016/j.jallcom.2015.05.224.

[45] T. Liu, Y. Gao, H. Bei, K. An, In situ neutron diffraction study on tensile deformation behavior of carbon-strengthened CoCrFeMnNi high-entropy alloys at room and elevated temperatures, J. Mater. Res. (2018) 1-12, https://doi.org/10.1557/jmr. 2018.180.

[46] H. Cheng, H.Y. Wang, Y.C. Xie, Q.H. Tang, P.Q. Dai, Controllable fabrication of a carbide-containing FeCoCrNiMn high-entropy alloy: microstructure and mechanical properties, Mater. Sci. Technol. 33 (2017) 2032-2039, https://doi.org/10.1080/ 02670836.2017 .1342367$.

[47] V.N. Sanin, V.I. Yukhvid, D.M. Ikornikov, D.E. Andreev, N.V. Sachkova, M.I. Alymov, SHS metallurgy of high-entropy transition metal alloys, Dokl. Phys. Chem. 470 (2016) 145-149, https://doi.org/10.1134/S001250161610002X.

[48] Z. Wu, H. Bei, F. Otto, G.M. Pharr, E.P. George, Recovery, recrystallization, grain growth and phase stability of a family of FCC-structured multi-component equiatomic solid solution alloys, Intermetallics 46 (2014), https://doi.org/10. 1016/j.intermet.2013.10.024.

[49] M. Odnobokova, M. Tikhonova, A. Belyakov, R. Kaibyshev, Development of $\Sigma 3 \mathrm{n}$ CSL boundaries in austenitic stainless steels subjected to large strain deformation and annealing, J. Mater. Sci. 52 (2017) 4210-4223, https://doi.org/10.1007/ s10853-016-0675-0.

[50] P.A. Beck, J.C. Kremer, L.J. Demer, M.L. Holzworth, Grain growth in high-purity aluminum and in an aluminum-magnesium alloy, Trans. AIME 175 (1948) 372-400.

[51] P.P. Bhattacharjee, G.D. Sathiaraj, M. Zaid, J.R. Gatti, C. Lee, C.W. Tsai, J.W. Yeh, Microstructure and texture evolution during annealing of equiatomic CoCrFeMnNi high-entropy alloy, J. Alloy. Compd. 587 (2014), https://doi.org/10.1016/j. jallcom.2013.10.237.

[52] G.D. Sathiaraj, P.P. Bhattacharjee, Effect of starting grain size on the evolution of microstructure and texture during thermo-mechanical processing of $\mathrm{CoCrFeMnNi}$ high entropy alloy, J. Alloy. Compd. (2015), https://doi.org/10.1016/j.jallcom. 2015.06.009.

[53] F. Otto, N.L. Hanold, E.P. George, Microstructural evolution after thermomechanical processing in an equiatomic, single-phase CoCrFeMnNi high-entropy alloy with special focus on twin boundaries, Intermetallics 54 (2014), https://doi. org/10.1016/j.intermet.2014.05.014.

[54] C.-C. Hsieh, W. Wu, Overview of intermetallic sigma ( ) phase precipitation in stainless steels, ISRN Metall. 2012 (2012) 1-16, https://doi.org/10.5402/2012/ 732471.

[55] O.N. Senkov, A.L. Pilchak, S.L. Semiatin, Effect of cold deformation and annealing on the microstructure and tensile properties of a HfNbTaTiZr refractory high entropy alloy, Metall. Mater. Trans. A (2018) 1-17, https://doi.org/10.1007/s11661018-4646-8.

[56] M. Hillert, On the theory of normal and abnormal grain growth, Acta Metall. 13 (1965) 227-238, https://doi.org/10.1016/0001-6160(65)90200-2.

[57] On Ardell, the coarsening of grain boundary precipitates/t, Acta Metall. 20 (1972) 601-609, https://doi.org/10.1016/0001-6160(72)90015-6.

[58] J.E. Burke, D. Turnbull, Recrystallization and grain growth, Prog. Met. Phys. 3 (1952) 220-292, https://doi.org/10.1016/0502-8205(52)90009-9.

[59] G.T. Higgins, Grain-boundary migration and Grain growth, Met. Sci. 8 (1974) 143-150, https://doi.org/10.1179/msc.1974.8.1.143.

[60] H. Hu, B.B. Rath, On the time exponent in isothermal grain growth, Metall. Trans. 1 (1970) 3181-3184, https://doi.org/10.1007/BF03038435.

[61] C.-C.C. Juan, M.-H.H. Tsai, C.-W.W. Tsai, W.-L.L. Hsu, C.-M.M. Lin, S.-K.K. Chen, S.J.J. Lin, J.-W.W. Yeh, Simultaneously increasing the strength and ductility of a refractory high-entropy alloy via grain refining, Mater. Lett. 184 (2016) 200-203, https://doi.org/10.1016/j.matlet.2016.08.060.

[62] A. Belyakov, Y. Sakai, T. Hara, Y. Kimura, K. Tsuzaki, Annealing behavior of submicrocrystalline oxide-bearing iron produced by mechanical alloying, Metall. Mater. Trans. A Phys. Metall. Mater. Sci. 34 (2003) 131-138, https://doi.org/10. 1007/s11661-003-0214-X.

[63] M.J. Gore, M. Grujicic, G.B. Olson, M. Cohen, Thermally activated grain boundary unpinning, Acta Metall. 37 (1989) 2849-2854, https://doi.org/10.1016/00016160(89)90320-9.

[64] E.O. Hall, The deformation and ageing of mild steel: III discussion of results, Proc. Phys. Soc. Sect. B 64 (1951) 747-753, https://doi.org/10.1088/0370-1301/64/9/ 303.

[65] T. Gladman, Precipitation hardening in metals, Mater. Sci. Technol. 15 (1999) 30-36, https://doi.org/10.1179/026708399773002782.

[66] P.S. Kusakin, R.O. Kaibyshev, High-Mn twinning-induced plasticity steels: microstructure and mechanical properties, Rev. Adv. Mater. Sci. 44 (2016) 326-360. 